\title{
Conserved mechanisms for putting pregnancy on hold in the mouse, mink and tammar wallaby
}

\author{
JC Fenelon ${ }^{1}$, G Shaw ${ }^{1}$, MB Renfree ${ }^{1}$ and BD Murphy ${ }^{2}$ \\ ${ }^{1}$ School of Biosciences, University of Melbourne, Victoria, Australia \\ ${ }^{2}$ Centre de recherche en reproduction et fertilité, Université de Montréal, Québec, Canada
}

Corresponding author email: feneloni@unimelb.edu.au

\begin{abstract}
Embryonic diapause was first identified over 150 years ago, but many questions still remain about how the external and hormonal controls of embryonic diapause translate into how the uterus conveys information to the embryo. Current evidence suggests that the control of diapause is mediated by components of the uterine secretions. However, the identity of the essential signalling molecule(s) is unknown. The mouse (Mus musculus), the mink (Neovison vison) and the tammar wallaby (Macropus eugenii) are the three most extensively studied mammalian diapause species. Despite differences in the external and hormonal control of diapause between these three species, we have now found that there is conservation of numerous molecular factors around diapause and reactivation. This was first suggested via the conserved expression of various growth factors. The first evidence for a conserved mechanism resulted from a study on the muscle segment homeobox transcription factor (MSX) in the uterus during diapause, whose expression is conserved amongst the mouse, mink and wallaby. Following this was the evidence that inhibition of polyamines induces entry into diapause in both the mink and mouse. Thus, although the signalling mechanisms via which the uterus is induced into diapause vary amongst species, the molecular communication that occurs between the uterus and the embryo to control diapause is conserved. Given that these mechanisms are conserved across varying taxa, this implies a universal mechanism for maintaining embryo health amongst all mammals. New technologies are now allowing us to examine diapause from a global perspective and to increase our knowledge of this enigmatic stage of pregnancy.
\end{abstract}

\section{Introduction}

Embryonic diapause is a common reproductive strategy amongst mammals, found in over 130 mammals in seven different orders. Diapause is a reproductive strategy where a naturally occurring, temporary arrest of the embryo occurs at the blastocyst stage to extend the period between mating and parturition to allow synchrony with environmental or seasonal changes. Whilst the endocrine control of pregnancy has been established in many diapause species, fundamental questions remain about the molecular control of embryonic diapause in all mammals that display this reproductive trait [1]. The three best characterized species for the study of embryonic diapause are the mouse (Mus musculus), mink (Neovison vison) and wallaby (Macropus eugenii) [2]. Furthermore, they represent all three modes of embryonic diapause: the mouse has facultative diapause where diapause is selectively induced due to lactational constraints; the mink has obligate diapause in which diapause is induced in every pregnancy in relation to seasonal changes and the wallaby has a combination of the two modes where lactational control occurs in the first half of the year and obligate (seasonal mode) takes over in the second half of the year 
(Table 1). A number of other characteristics of diapause differ amongst these three species including the length of diapause and their hormonal control mechanisms, as detailed below (Table 1).

\section{Mechanisms of mouse diapause}

In the mouse, diapause is facultative and results from lactational metabolic stress. It can also be experimentally induced (Cha et al this volume). The mouse exhibits post-partum mating within 14$28 \mathrm{~h}$ of parturition [3]. The sucking stimulus of the litter then prevents the ovarian oestrogen pulse on day 4 of embryo development that initiates the implantation process. However, the length of diapause is dependent on the number of suckling young [4, 5](Table 1). During diapause, the blastocyst gradually slows its rate of cell proliferation over a period of $72 \mathrm{~h}$ and its rates of protein synthesis and carbohydrate metabolism are greatly reduced [6, 7]. Mice and rats were the first diapause species to be extensively examined for the control of diapause, partly due to the ease in which diapause can be experimentally induced. The classic model involves ovariectomy before $0900 \mathrm{~h}$ on $\mathrm{d} 4 \mathrm{~d}$ of pregnancy and maintenance via daily progesterone $\left(\mathrm{P}_{4}\right)$ injections. Alternatively, diapause can be induced by a single injection of an anti-oestrogen (ICI182,780) [8]. Reactivation requires a single injection of oestrogen $\left(E_{2}\right)$ with rapid resumption of the cell cycle, metabolism and DNA, RNA and protein synthesis with implantation occurring within 24h [9-11]. Under experimental conditions, diapause can be induced for up to 10 days, after this time, blastocysts begin to show compromised developmental competence and the proportion that are able to implant decreases (Weitlauf \& Greenwald 1968, Lee et al 2011).

Table 1: Comparison of the external and endocrine control of diapause and reactivation between the mouse, mink and wallaby including the time taken for the embryo to implant after reactivation from diapause.

$\begin{array}{llll}\text { Type of diapause } & \begin{array}{l}\text { mouse } \\ \text { facultative } \\ \text { (lactational) }\end{array} & \begin{array}{l}\text { mink } \\ \text { obligate (seasonal) }\end{array} & \begin{array}{l}\text { wallaby } \\ \text { facultative \& obligate } \\ \text { (lactational \& seasonal) }\end{array} \\ \begin{array}{l}\text { Length of diapause } \\ \text { (naturally induced) }\end{array} & 1-14 \text { days } & 6 \text { days-3 weeks } & 11 \text { months } \\ \begin{array}{l}\text { Time to } \\ \text { implantation }\end{array} & 24 \text { hours } & 13-14 \text { days } & 18 \text { days* } \\ \begin{array}{l}\text { Reactivation } \\ \text { hormone }\end{array} & \text { oestrogen } & \begin{array}{l}\text { prolactin } \\ \text { (progesterone) }\end{array} & \text { progesterone }\end{array}$

* Note the wallaby does not implant but hatches from the shell coat at d18 of reactivation (equivalent to day 18 of removal of pouch young, RPY) and then attaches to the uterine wall, 9-10 days before birth.

\section{Mechanisms of mink diapause}

In the mink diapause is obligatory, being seasonally induced, and extends for variable durations prior to implantation (Murphy \& Fenelon this volume). Briefly, the proximal signal responsible for reactivation of the mink blastocyst from diapause is prolactin secreted from the pituitary gland, under the influence of the vernal equinox, which reactivates the dormant corpus luteum to rapidly increase progesterone synthesis [12]. Exogenous prolactin administered during diapause (d0 PRL) 
can induce and synchronize reactivation [12-14]. During diapause, the mink blastocyst maintains an almost complete arrest of the cell cycle and a greatly reduced metabolism, DNA and protein synthesis [15]. The first signs of reactivation from diapause are increased DNA and protein synthesis in the embryo on the third day after prolactin injection (d3 PRL), with the first expansion of the blastocyst occurring at day 4 PRL and implantation between day 13-14 PRL [15].

\section{Mechanisms of wallaby diapause}

The tammar wallaby can sequentially undergo a facultative, lactational delay during the first half of the year and a seasonal, obligate diapause after the winter solstice $\left(22^{\text {nd }}\right.$ June, in the Southern hemisphere), thus maintaining the embryo in diapause for up to 11 months of the year [16-18]. The tammar mates 1-3h after birth [19] and it is the neural stimulus of the newly born sucking pouch young that releases prolactin and inhibits the luteal progesterone pulse causing the blastocyst and the corpus luteum to enter into diapause by d8 postpartum $[1,20]$. For reactivation, the luteal inhibition needs to be removed for 3 days, induced by removal of the pouch young (d0 RPY), and this results in a progesterone pulse around day 4 [21-24]. This pulse stimulates the production of uterine secretions that reactivate the blastocyst - characterised by a resumption of mitosis and a switch to an oxidative metabolism at d4 RPY with expansion by d8 RPY [25-30]. However, if the pouch young is removed after the winter solstice (June $22^{\text {nd }}$ in the Southern hemisphere), the blastocyst will not reactivate and will remain in seasonal diapause until after the summer solstice (December $22^{\text {nd }}$ ). Seasonal diapause is controlled by the pineal gland and release of melatonin in response to the changing length of the night [30-32]. Thus, due to this seasonal synchrony, reactivation is synchronised, and while all tammar wallabies give birth around the end of January, the hottest, driest month, the pouch young are all weaned by October after the spring growth.

\section{Conserved mechanisms}

Although there is variation amongst the three species in the mechanisms of diapause and the specific endocrine signals required, each result in the control and regulation of the uterus. The uterine environment then controls whether the embryo enters into, and exits, diapause. It is known that this uterine control requires an intimate crosstalk between the endometrium and the embryo, but the precise molecular signals involved have not been clearly defined. The first indication that the molecular mechanisms of diapause could be conserved amongst mammals came from growth factor expression studies.

A member of the epidermal growth factor (EGF) family, heparin-binding EGF (HBEGF), was the first growth factor to be implicated in blastocyst reactivation from diapause in the mouse. Implantation in the mouse occurs within $24 \mathrm{~h}$ of the oestrogen signal at $0900 \mathrm{~h}$ of the day of reactivation (or $\mathrm{d} 4 \mathrm{in}$ the non-diapause model) and HBEGF is first expressed in the uterus at 1600h [33]. This is one of the earliest expressed uterine reactivation factors in the mouse and this expression pattern is similar in both the wallaby and the mink reactivated uterus [34, 35]. Furthermore, members of the EGF family receptors are expressed in the blastocyst at reactivation of the mouse, mink and wallaby [36]

LIF is a member of the IL- 6 cytokine family and is essential for reactivation from diapause and implantation in the mouse [37]. In the mouse, LIF is absent during diapause and expressed at reactivation in the uterine luminal epithelium [38]. In the uterus, LIF activates the Jak-Stat pathway by binding to the heterodimeric LIF receptor complex consisting of the LIF receptor (LIFR) and glycoprotein 130 (gp130). LIFR and gp130 are also expressed in the luminal and glandular epithelium and conditional knockout of gp130 results in a failure of implantation $[39,40]$. Similar to the mouse, in both the mink and western spotted skunk, another diapause mammal, LIF is absent from the uterus during diapause and increases at reactivation [41,42] whilst in the tammar, LIF has 
very low expression in the uterus during diapause and increases significantly at reactivation (MB Renfree, unpublished results).

As many of these growth factor studies were limited by the examination of expression data only, there is a lack of functional evidence to provide a definitive role for any in controlling embryonic diapause. The first factor to be confirmed as affecting whether embryos enter into diapause or not, and with an expression pattern that was conserved amongst diapause species was MSX (Cha et al, this volume). In brief, MSX is expressed in the uterus of the mouse, mink and wallaby during diapause, and its expression is required to cease for reactivation to occur. Conditional knockout studies in the mouse further showed that the presence of MSX in the uterine luminal epithelium is essential for the maintenance of diapause [8].

Following on from MSX was the discovery that polyamines are essential for reactivation of the embryo from diapause in both the mink and the mouse. Polyamines are small non-aliphatic compounds, essential for many cellular pathways, including proliferation, due to their ability to bind to, and interact with, nucleic acids and proteins [43]. Their synthesis is tightly regulated by a system of enzymes and feedback pathways, primarily via the rate limiting enzyme ornithine decarboxylase 1 (ODC1). The first evidence that polyamines could be involved in embryonic diapause was from studies in the mink which showed that ODC1, and two other polyamine pathway enzymes SAT1 and AZIN1, are significantly increased at reactivation in both the embryo and the uterus [44-46]. Confirmation of the essential role for polyamines came from in vivo studies where treatment of females at reactivation with an inhibitor of ODC1, difluromethylornithine (DFMO), caused the blastocysts to re-enter diapause with significant reductions in the concentrations of the polyamines in the uterus [46]. Similarly, treating mice in vivo from $\mathrm{d} 4$ of pregnancy with DFMO causes the blastocysts to enter into diapause and disrupts expression of a number of implantation-related genes, including HBEGF [47]. Finally, in both the mink and the mouse, in vivo DFMO treatment decreases expression of multiple enzymes in the polyamine pathway (Box1).

In the mouse, levels of Amd1 and Azin1 increase in the uterus in response to DFMO treatment compared to diapause whilst levels of Odc1 and Sat1 remain the same [47]. In contrast, in the mink, SAT1 was significantly decreased in the DFMO-treated uteri to levels consistent with diapause whilst ODC1 and AZIN1 expression only showed a trend towards a decrease, which was not significantly different from either the diapause or control uteri. This could potentially indicate a partial compensation for ODC1 and AZIN1 expression in response to the DFMO treatment. Similarly, in the mouse, a number of genes related to implantation are decreased after DFMO treatment compared to the untreated uteri, whilst MSX1 expression was maintained [47]. In the mink, there were no significant differences in any of the non-polyamine pathway genes examined including the hormonal receptors, MSX1 or the EGF family. However, many of these genes are posttranslationally regulated and therefore may not necessarily show a significant difference in expression at the gene level.

Polyamines directly affect reactivation of the mink blastocyst. In vitro addition of the polyamine putrescine to the mink diapause blastocyst increases both survival rates and proliferation - both hallmarks of reactivation from diapause [44]. Similarly, the addition of putrescine to either a mink trophoblast or inner cell mass (ICM) cell lines increases proliferation whilst DFMO treatment decreases proliferation. In contrast, mouse diapause blastocysts are able to spontaneously reactivate in vitro and this includes after DFMO-induced diapause [47]. These results indicate that the requirement of the embryo for polyamines at reactivation is a uterine effect. Our current hypothesis is that DFMO dysregulates the communication between the endometrium and the embryo, indicating the importance of polyamine availability in regulating embryonic diapause. 


\section{Experimental verification: Downstream effects of polyamine inhibition in the mink}

In order to examine in more detail the downstream effects of polyamines in the mink, DFMO treatment of reactivated females was repeated following the protocol in [46]. All other experimental procedures regarding immunofluorescence and qPCR data and analysis were as previously reported $[44,47]$. Prolactin (PRL) was administered to all treatment animals to terminate diapause. Briefly, pregnant female mink were treated daily with prolactin and either DFMO or saline from d0 for five days. Mink were then euthanised on d6 PRL and the uteri flushed. A control group at diapause (equivalent to dO PRL) were also euthanised and the uteri flushed for comparison. When initially flushed from the uterus, mink embryos shrink away from their shell coat but after $24 \mathrm{~h}$ in culture, the majority are able to recover. Embryos flushed from the saline-treated controls were significantly larger compared to the DFMO-treated embryos $(p=0.005)$ and diapause blastocysts $(p<0.0001$ ) based on capsule diameter (Figure $2 A)$. The embryos collected on $d 6 \mathrm{PRL}$ were unable to recover from their original shrinkage, presumably due to their size (Figure 2A)[61]. After DFMO treatment, mink embryos had significantly reduced rates of proliferation, confirming their diapause state, consistent with the previous study [46]. In uteri of treated animals, the proliferation marker MKI67 expression was decreased to a similar level to the diapause controls compared to the reactivated controls, indicating that the DFMO-treated uterus resembled a diapause-like state (Figure 2B).

We examined the effects of compromised polyamine synthesis in vivo after treatment with DFMO. In the uterus, there was a significant difference in expression between diapause and reactivation for the polyamine enzymes ODC1, SAT1, AZIN1 and the growth factor HBEGF (Figure 3). However, in the DFMO-treated uteri, there was no significant difference in the expression of any of the genes examined, except for SAT1, where the levels after DFMO treatment were significantly decreased from reactivation. The expression of the remaining genes examined (SAMDC, PRLR, PGR, ESR1, $M S X 1$ and $E G F R$ ) remained constant throughout diapause, reactivation and after DFMO treatment (Figure 3). 
A
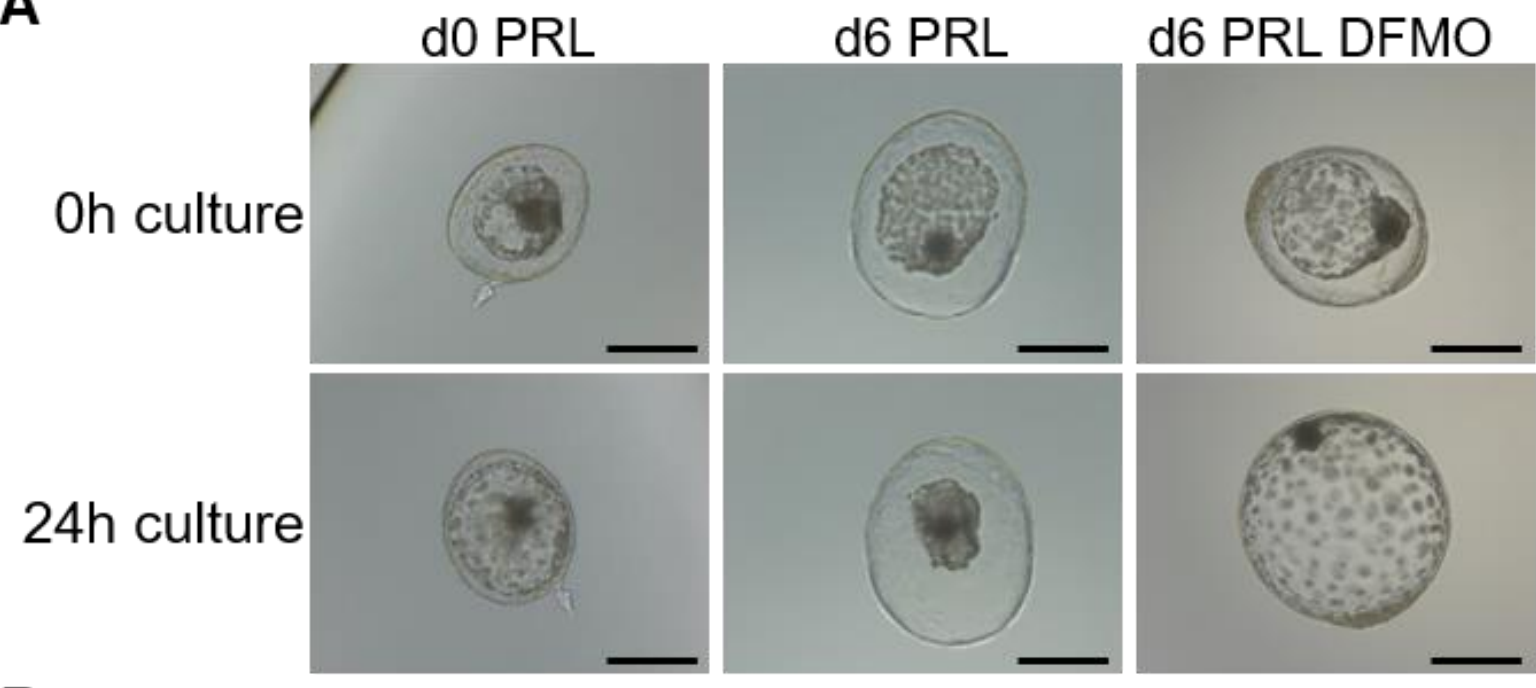

B
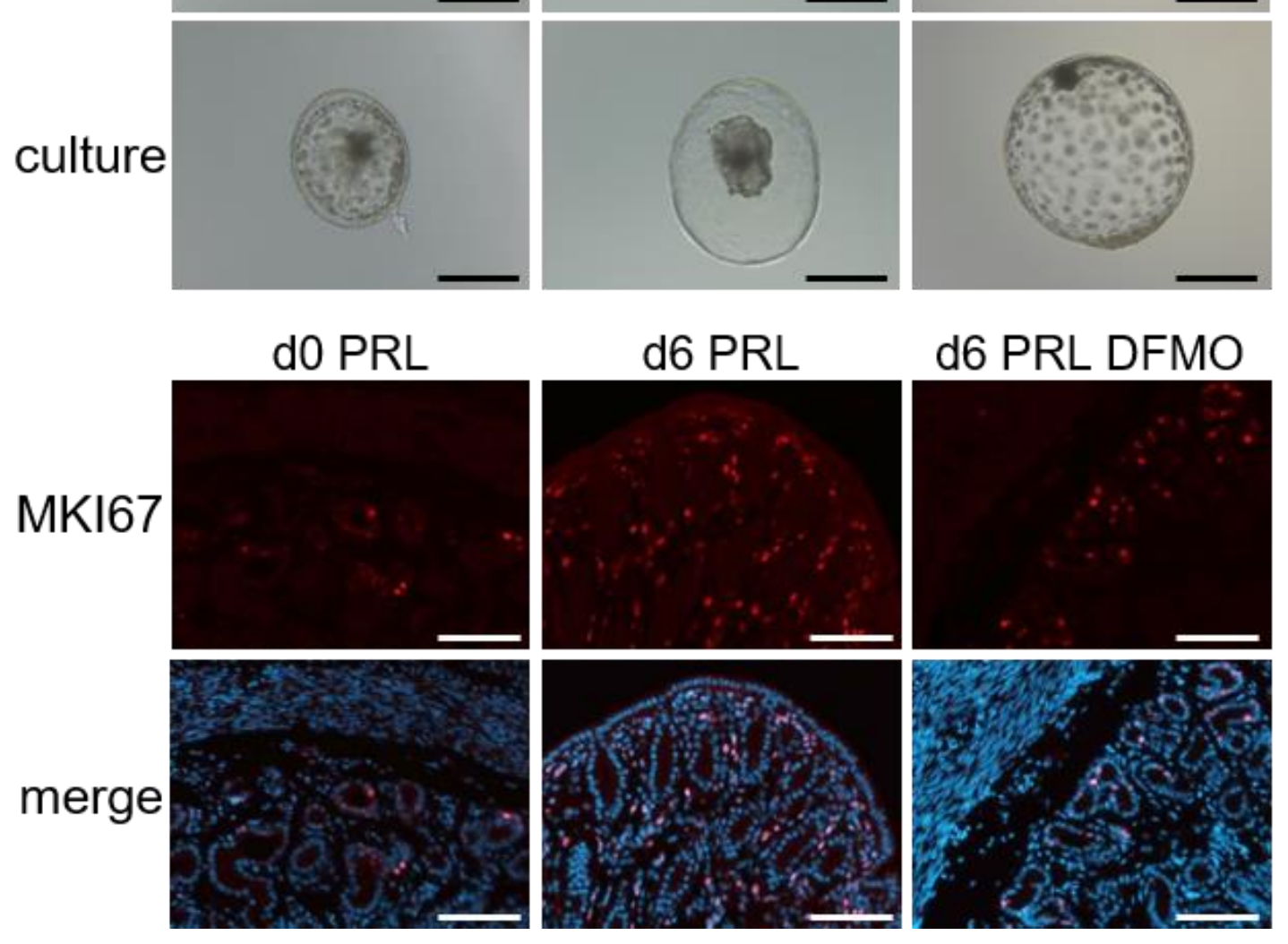

Figure 1: Effect of DFMO treatment in the mink on growth of embryos and the proliferation state of the uterus

A: When first flushed (Oh), d6 PRL, embryos were significantly larger than both d0 PRL (diapause) and DFMO treated embryos, but DFMO-treated embryos were also significantly larger than d0 PRL embryos, based on capsule volume. Over $24 \mathrm{~h}$ in culture, d6 PRL embryos were unable to recover from their original shrinkage, B: MKI67 was detected in the nucleus of the glandular and luminal epithelium at all stages examined and was increased at reactivation. Red represents the staining of the protein of interest, blue indicates DAPI nuclear stain and the merge shows both channels. $d 0 \mathrm{PRL}=$ diapause control embryo, $\mathrm{d} 6 \mathrm{PRL}=$ vehicle control treated embryo, reactivated, DFMO $=$ d6 PRL DFMO-treated embryo and MKI67: marker of proliferation (Ki-67). All embryo pictures taken at same magnification, scale bar $=200 \mu \mathrm{m}$. All immunofluorescence photos taken at the same magnification, scale bar $=100 \mu \mathrm{m}$ at $20 \mathrm{x}$ magnification. 

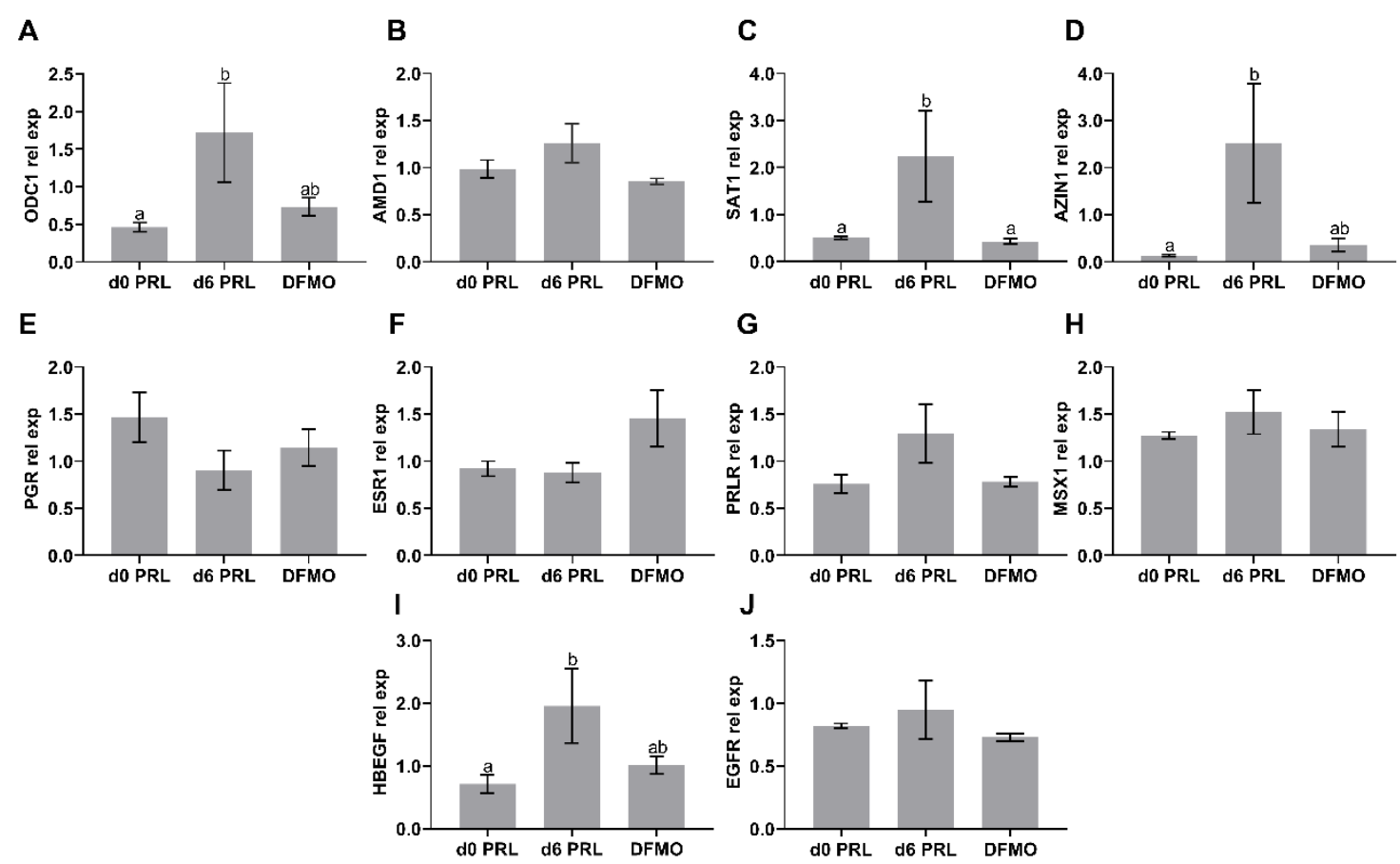

Figure 2: mRNA qPCR expression profile of polyamine pathway genes across diapause (d0 PRL), reactivation controls (d6 PRL) and DFMO treated uteri. Data represent mean mRNA abundance of each gene relative to the expression of the housekeeping genes RPS18 and HPRT1. All values represent mean a SEM with $\mathrm{n}=5$ samples per stage and means bearing different superscripts are different at $p<0.05$. A: ODC1 (ornithine decarboxylase 1); B: AMD1 (adenosylmethionine decarboxylase 1); C: SAT1 (N1-Spermidine/Spermine acetyltransferase); D: AZIN1 (antizyme inhibitor 1); E: PGR (Progesterone receptor); F: ESR1 (Oestrogen receptor 1), G: PRLR (prolactin receptor), H: MSX1 (msh homeobox 1); I: HBEGF (heparin binding epidermal growth factor-like like growth factor); J: EGFR (epidermal growth factor receptor). rel exp: relative expression, diapause: day 0 PRL, react: $d 6$ PRL vehicle control treated, DFMO: d6 PRL DFMO-treated.

\section{New technologies}

Numerous other factors have also been implicated in reactivation from diapause (for review refer to [36]). While many of these have similar expression patterns in multiple diapause mammals, a definitive role for any of them is lacking. Furthermore, there is likely to be considerable overlap and redundancy amongst them and confirming whether a factor is essential is laborious and requires independent assessment of each. New technologies have allowed us to now begin to examine diapause from a global perspective and start to identify the conserved downstream pathways involved.

The earliest study to examine diapause from a global view compared diapause versus reactivated mouse embryos and identified 229 differentially expressed genes by microarray analysis [48]. This study confirmed the involvement of predicted pathways (i.e. cell cycle and metabolism) but also highlighted the importance of calcium signalling and chromatin remodelling for reactivation [48]. More recently, the proteome of the diapause and reactivated mouse embryo has been investigated [49]. This study identified 277 proteins specific to the diapause blastocyst and 585 proteins found only in the reactivated blastocysts [49]. Analysis of these proteins revealed that at reactivation the blastocyst requires an increase in aerobic glycolysis, upregulation of nucleotide biosynthesis and activation of mitochondrial function [49]. Thus, the diapause and reactivated blastocyst are each an active unit with their own complex and interacting signalling pathways.

The first global mink studies performed suppressive subtractive hybridisation (SSH) on the mink uteri at reactivation and identified 123 differentially expressed genes that included enrichment for 
cell proliferation, cell homeostasis, and was the first study to identify the importance of polyamines [45]. A follow-up SSH study on the diapause and reactivated embryo found upregulation of 216 transcripts at reactivation, including genes in the polyamine pathway [44]. Recently, a more comprehensive study was performed focussing on the transcriptome of the diapause and reactivated mink uterus using RNA-Seq. This study identified 564 genes up-regulated during diapause and 963 genes up-regulated at reactivation [50]. Whilst the most significantly enriched pathways at reactivation were for endometrial morphological changes and functions, there were also increases in genes related to prolactin signalling and downstream pathways of growth factor signalling including G-protein coupled receptor (GPCR) activity and the PI3K-Akt pathway. Finally, a number of genes, including EGF, were identified as critical based on protein-protein interaction network analysis confirming previous work into the importance of these factors during reactivation [50].

Analysis of the uterine fluid proteome has also been examined in the tammar wallaby and the roe deer, another diapause mammal, during diapause and reactivation [35, 51]. In the roe deer 107 differentially expressed proteins were identified comparing the three different stages of diapause (early-, mid- and late-diapause) and reactivation (elongation). This analysis identified a number of clusters that supported embryo development during diapause and cell cycle promoters at elongation, consistent with the requirement for reactivation of the cell cycle after diapause [51]. However, note that the roe deer embryo continues to undergo a slow period of growth during diapause [52]. In the tammar, the majority of the 603 uterine fluid proteins were present at all stages examined, of which 128 were secretory [35]. However, cell cycle regulatory proteins were only present during diapause whilst between days 4-6 RPY (early reactivation) there was an increase in growth factors including soluble transforming growth factor beta (TGF- $\beta$ ), EGFR and heparin binding growth factor (HDGF, previously known as hepatoma-derived growth factor) [35]. In the d0-d3 RPY samples only, there were proteins present that are involved in the p53/p21 cell cycle inhibition pathway, whilst in the reactivation samples the cell proliferation and differentiation markers galectin 1 (LGALS1) and proliferating cell nuclear antigen (PCNA), were present [35]. These studies highlight the importance of communication between the uterus and the embryo in controlling the events of diapause and reactivation, but it is unknown what proportion of these factors came from the uterus, embryo or both.

Finally, in mice there are at least 38 microRNAs (miRNAs) in the blastocyst that are upregulated at diapause compared to reactivation [53]. Similarly, there are 42 miRNAs upregulated in the mouse uterus at diapause [54]. In particular, the lethal-7 (let-7) family of miRNAs appear to have an important role during diapause. Members of this family are upregulated in the mouse at diapause in the blastocyst and the uterus and a partial diapause-like state can be induced by overexpression of let-7a in the embryo $[55,56]$. MiRNAs are essential to embryo development in general and it is likely that other miRNAs are also involved in the control of diapause as their primary role is to suppress translation post-transcriptionally [57]. However, a confirmed function for the majority of the miRNAs identified in the mouse during diapause has not been established [53]. No other diapause species have yet been examined. 


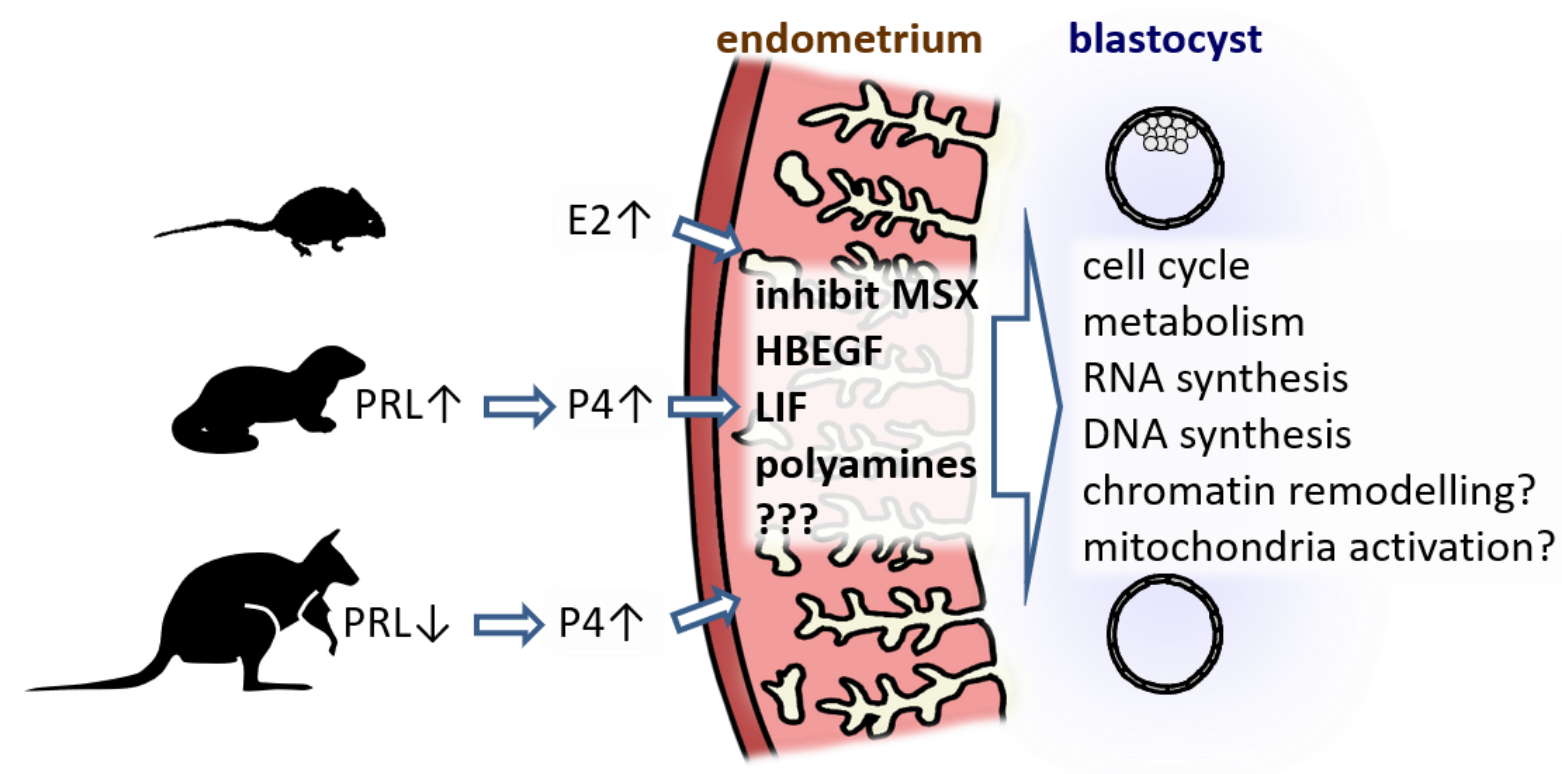

Figure 3: Overview of the evolutionarily conserved processes involved at reactivation from diapause in the mouse, mink and wallaby. Despite the varying hormonal mechanisms required to reactivate the endometrium between the mouse, mink and wallaby, a number of factors have been identified that are conserved amongst all three. At reactivation, these include a decrease in MSX expression and an upregulation of HBEGF, LIF and polyamine related enzymes in the endometrium. However, it is predicted that other factors are also required. These uterine signals then cause reactivation of the blastocyst which requires activation of a number of pathways, for example a resumption of the cell cycle and an increased metabolism. The challenge remains in identifying the essential mechanisms via which this occurs. Note, the tammar blastocyst is unilaminar and it is unknown which cells of the blastocyst form the inner cell mass. E2: oestradiol, PRL: prolactin, P4: progesterone, MSX: muscle segment homeobox transcription factor, HBEGF: heparin-binding epidermal growth factor, LIF: leukemia inhibitory factor.

\section{Future challenges}

Despite these extensive new studies, the essential pathways that maintain the diapause state and induce reactivation remain an enigma. Previously it was thought that diapause and reactivation would be controlled by only a few pathways. However, advances in technology are now beginning to highlight the complexity of the processes involved that control diapause and reactivation. What is clear is that the mechanisms of diapause and reactivation require a number of regulatory and secretory pathways in both the uterus and the embryo (Figure 1). In the embryo these include regulation of the cell cycle, control of metabolism and control of DNA and RNA synthesis. Additional processes that may be required at reactivation include chromatin remodelling and activation of mitochondria. Growth factors also appear to be operating in an integrated network between the uterus and embryo, with many activating multiple pathways. This suggests a degree of redundancy in the system. The polyamines appear to be among the essential factors, but it is currently not known how they act. More studies are needed to clarify the complex interactions of the downstream pathways, upon which many of the upstream regulatory factors appear to converge. These include $\mathrm{Ca}^{2+}$ signalling, the PI3K-Akt pathway and GPCR signalling. At least some of these pathways appear conserved amongst the species examined to date. Recent work has also identified the importance of the MYC and MTOR signalling pathways as essential to the control of both diapause and stem cell pluripotency, at least in the mouse $[58,59]$. There is only limited investigation of miRNAs into the regulation of diapause but the evidence so far suggests they could have an important function in controlling the embryo during diapause [55, 56]. Finally, a recent paper has identified distinct transcript splicing variants in the diapause mouse embryo that could 
be important for maintaining the diapause state [60]. Thus, new -omics technologies are now allowing us to gain greater insight than ever before into the mechanisms of diapause and the challenge will be to integrate all this information into a cohesive model by which diapause is controlled.

\section{Declaration of interest}

The authors declare no conflicts of interest.

\section{Funding}

The authors original research on the mink reported herein received funding from a Discovery Grant (137013) from the National Sciences and Engineering Research Council to BD Murphy and a postdoctoral fellowship from the Canadian Institutes of Health Research to JC Fenelon.

\section{References}

[1] Renfree MB and Shaw G. 2000 Diapause. Annual Review of Physiology 62 353-375.

[2] Fenelon JC, Banerjee A and Murphy BD. 2014 Embryonic diapause: development on hold. Int J Dev Biol 58 163-174.

[3] Long JA and Mark EL. 1911 The maturation of the egg of the mouse. Carnegie Institution of Washington 142 1-72.

[4] Daniel JF. 1910 Observations on the period of gestation in white mice. Jour Exp Zool 9 865-870.

[5] Mantalenakis SJ and Ketchel MM. 1966 Frequency and extent of delayed implantation in lactating rats and mice. Journal of Reproduction and Fertility 12 391-394.

[6] McLaren A. 1968 A study of blastocysts during delay and subsequent implantation in lactating mice. Journal of Endocrinology 42 453-463.

[7] Weitlauf HM. 1974 Metabolic changes in the blastocysts of mice and rats during delayed implantation. Journal of Reproduction and Fertility 39 213-224.

[8] Cha J, Sun X, Bartos A, Fenelon JC, Lefevre P, Daikoku T, Shaw G, Maxson R, Murphy BD, Renfree MB and Dey SK. 2103 A new role for muscle segment homeobox genes in mammalian embryonic diapause. Open Biol 3130035.

[9] Paria BC, Huet-Hudson YM and Dey SK. 1993 Blastocyst's state of activity determines the "window" of implantation in the receptive mouse uterus. Proceedings of the National Acadamy of Science 90 1015910162.

[10] Spindler RE, Renfree MB and Gardner DK. 1996 Carbohydrate uptake by quiescent and reactivated mouse blastocysts. The Journal of Experimental Zoology 276 132-137.

[11] Yoshinaga K and Adams CE. 1966 Delayed implantation in the spayed, progesterone treated adult mouse. Journal of Reproduction and Fertility 12 593-595.

[12] Murphy BD, Concannon PW, Travis HF and Hansel W. 1981 Prolactin: the hypophyseal factor that terminates embryonic diapause in mink. Biology of Reproduction 25 487-491.

[13] Papke RL, Concannon PW, Travis HF and Hansel W. 1980 Control of luteal function and implantation in the mink by prolactin. Journal of Animal Science 50 1102-1107.

[14] Stoufflet I, Mondain-Monval M, Simon P and Martinet L. 1989 Patterns of plasma progesterone, androgen and oestrogen concentrations and in-vitro ovarian steroidogenesis during embryonic diapause and implantation in the mink (Mustela vison). J Reprod Fert 87 209-221.

[15] Desmarais JA, Bordignon V, Lopes FL, Smith LC and Murphy BD. 2004 The escape of the mink embryo from obligate diapause. Biology of Reproduction 70 662-670.

[16] Fenelon JC and Renfree MB. 2018 The history of the discovery of embryonic diapause in mammals. 
Biol Reprod 99(1) 242-251.

[17] Renfree MB. 1979 Initiation of development of diapausing embryo by mammary denervation during lactation in a marsupial. Nature 278(5704) 549-551.

[18] Renfree MB, Lincoln DW, Almeida OF and Short RV. 1981 Abolition of seasonal embryonic diapause in a wallaby by pineal denervation. Nature 293(5828) 138-9.

[19] Rudd CD. 1994 Sexual behaviour of male and female tammar wallabies (Macropus eugenii) at postpartum oestrus. J Zool Lond 232 151-162.

[20] Renfree MB, Green SW and Young IR. 1979 Growth of the corpus luteum and its progesterone content during pregnancy in the tammar wallaby, Macropus eugenii. Journal of Reproduction and Fertility 57 131-136.

[21] Gordon K, Fletcher TP and Renfree MB. 1988 Reactivation of the quiescent corpus luteum and diapausing embryo after temporary removal of the sucking stimulus in the tammar wallaby (Marcropus eugenii). Journal of Reproduction and Fertility 83 401-406.

[22] Hinds LA, Evans SM and Tyndale-Biscoe CH. 1982 In-vitro secretion of progesterone by the corpus luteum of the tammar wallaby, Macropus eugenii. Journal of Reproduction and Fertility 67 57-63.

[23] Hinds LA and Tyndale-Biscoe CH. 1982 Plasma progesterone levels in the pregnant and non-pregnant tammar, Macropus eugenii. Journal of Endocrinology 93 99-107.

[24] Shaw G and Renfree MB. 1984 Concentrations of oestradiol-17 $\beta$ in plasma and corporea lutea throughout pregnancy in the tammar, Macropus eugenii. Journal of Reproduction and Fertility 72 29-37.

[25] Denker HW and Tyndale-Biscoe CH. 1986 Embryo implantation and proteinase activities in a marsupial (Macropus eugenii). Cell Tissue Res 246 279-291.

[26] Renfree MB. 1994 Endocrinology of pregnancy, parturition and lactation in marsupials, in Pregnancy and Lactation Part 2 Fetal physiology parturition and lactation, Lamming, G.E., Editor. Chapman \& Hall: London 677-766.

[27] Shaw G. 1996 The uterine environment in early pregnancy in the tammar wallaby. Reproduction Fertility Development 8 811-818.

[28] Spindler RE, Renfree MB, Shaw G and Gardner DK. 1998 Reactivating tammar wallaby blastocysts oxidise glucose. Biology of Reproduction 58 1425-1431.

[29] Thornber EJ, Renfree MB and Wallace GI. 1981 Biochemical studies of intrauterine components of the tammar wallaby Macropus eugenii during pregnancy. Journal of Embryology and Experimental Morphology 62 325-338.

[30] Tyndale-Biscoe CH and Renfree MB. 1987 Reproductive Physiology of Marsupials. Cambridge: Cambridge University.

[31] Renfree MB, Lincoln DW, Almeida OFX and Short RV. 1981 Abolition of seasonal embryonic diapause in a wallaby by pineal denervation. Nature 293 138-139.

[32] Tyndale-Biscoe CH, Hinds LA and McConnell SJ. 1986 Seasonal breeding in a marsupial: opportunites of a new species for an old problem. Recent Progress in Hormone Research 42 471-512.

[33] Das SK, Wang XN, Paria BC, Damm D, Abraham JA, Klagsbrun M, Andrews GK and Dey SK. 1994 Heparin-binding EGF-like growth factor gene is induced in the mouse uterus temporally by the blastocyst solely at the site of apposition: a possible ligand for interaction with blastocyst EGF-receptor in implantation. Development 120 1071-1083.

[34] Fenelon JC, Shaw G, Frankenberg SR, Murphy BD and Renfree MB. 2017 Embryo arrest and reactivation: potential candidates controlling embryonic diapause in the tammar wallaby and mink. Biology of Reproduction 96(4) 877-894.

[35] Martin FC, Ang CS, Gardner DK, Renfree MB and Shaw G. 2016 Uterine flushing proteome of the tammar wallaby after reactivation from diapause. Reproduction.

[36] Renfree MB and Fenelon JC. 2017 The enigma of embryonic diapause. Development 144 3199-3210.

[37] Stewart CL, Kaspar P, Brunet LJ, Bhatt H, Gadi I, Köntgen F and Abbondanzo SJ. 1992 Blastocyst implantation depends on maternal expression of leukemia inhibitory factor. Nature 359 76-79.

[38] Bhatt $\mathrm{H}$, Brunet $\mathrm{L}$ and Stewart CL. Uterine expression of leukemia inhibitory factor coincides with 
the onset of blastocyst implantation. Proceedings of the National Acadamy of Science USA Developmental Biology 88 11408-11412.

[39] Cheng JG, Chen JR, Hernandez L, Alvord WG and Stewart CL. 2001 Dual control of LIF expression and LIF receptor function regulate Stat3 activation at the onset of uterine receptivity and embryo implantation. Proceedings of the National Acadamy of Science 98(15) 8680-8685.

[40] Sun X, Bartos A, Whitsett JA and Dey SK. 2013 Uterine depletion of Gp130 or Stat3 shows implantation failure with increased estrogenic responses. Molecular Endocrinology 27(9) 1492-1501.

[41] Hirzel DJ, Wang J, Das SK, Dey SK and Mead RA. 1999 Changes in uterine expression of Leukemia Inhibitory Factor during pregnancy in the Western Spotted Skunk. Biology of Reproduction 60 484-492.

[42] Song JH, Houde A and Murphy BD. 1998 Cloning of Leukemia Inhibitory Factor (LIF) and its expression in the uterus during embryonic diapause and implantation in the mink (Mustela vison). Molecular Reproduction and Development 51 13-21.

[43] Miller-Fleming L, Olin-Sandoval V, Campbell K and Ralser M. 2015 Remaining mysteries of molecular biology: the role of polyamines in the cell. Journal of Molecular Biology 427(21) 3389-3406.

[44] Fenelon JC, Banerjee A, Lefèvre P, Gratin F and Murphy BD. 2016 Polyamine-mediated effects of prolactin dictate emergence from mink obligate embryonic diapause. Biology of Reproduction 95(6) 1-13.

[45] Lefèvre PLC, Palin MF, Beaudry D, Dobias-Goff M, Desmarais J, Llerena EM and Murphy BD. 2011 Uterine signaling at the emergence of the embryo from obligate diapause. Am J Physiol Endocrinol Metab 300 E800-E808.

[46] Lefèvre PLC, Palin MF, Chen G, Turecki G and Murphy BD. 2011 Polyamines are implicated in the emergence of the embryo from obligate diapause. Endocrinology 152.

[47] Fenelon JC and Murphy BD. 2017 Inhibition of polyamine synthesis causes entry of the mouse blastocyst into embryonic diapause. Biology of Reproduction 97(1) 119-132.

[48] Hamatani T, Daikoku T, Wang H, Matsumoto H, Carter MG, Ko MSH and Dey SK. 2004 Global gene expression analysis identifies molecular pathways distinguishing blastocyst dormancy and activation. Proceedings of the National Acadamy of Science 101(28) 10326-10331.

[49] Fu Z, Wang B, Wang S, Wu W, Wang Q, Chen Y, Kong S, Lu J, Tang Z, Ran H, Tu Z, He B, Zhang S, Chen Q, Jin W, Duan E, Wang H, Wang YI, Li L, Wang F, Gao S and Wang H. 2014 Integral proteomic analysis of blastocysts reveals key molecular machinery governing embryonic diapause and reactivation for implantation in mice. Biology of Reproduction 90(3) 1-11.

[50] Cao X, Zhao J, Liu Y, Ba H, Wei H, Zhang Y, Wang G, Murphy BD and Xing X. 2019 Transcriptome changes in the mink uterus during blastocyst dormancy and reactivation. International Journal of Molecular Sciences 202099.

[51] Van der Weijden VA, Bick JT, Bauersachs S, Arnold GJ, Fröhlich T, Drews B and Ulbrich SE. 2019 Uterine fluid proteome changes during diapause and resumption of embryo development in roe deer (Capreolus capreolus). Reproduction 158 13-24.

[52] Aitken RJ. 1981 Aspects of delayed implantation in the roe deer (Capreolus capreolus), in Embryonic diapause in mammals, Flint APF, Renfree MB and Weir BJ, Editors. The Journals of Reproduction and Fertility Ltd: Cambridge, U.K. 83-95.

[53] Liu WM, Pang RT, Cheong AW, Ng EH, Lao K, Lee KF and Yeung WS. 2012 Involvement of microRNA lethal-7a in the regulation of embryo implantation in mice. PLoS Biology 7(5) e37039.

[54] Su RW, Lei W, Liu JL, Zhang ZR, Jia B, Feng XH, Ren G, Hu SJ and Yang ZM. 2010 The integrative analysis of microRNA and mRNA expression in mouse uterus under delayed implantation and activation. PLoS Biology 5(11) e15513.

[55] Wang H, Matsumoto H, Guo Y, Paria BC, Roberts RL and Dey SK. 2003 Differential G protein-coupled cannabinoid receptor signaling by anandamide directs blastocyst activation for implantation. Proceedings of the American Philosphical Society 100(25) 14914-14919.

[56] Liu GY, Hung YC, Hsu PC, Liao YF, Chang WH, Tsay GJ and Hung HC. 2005 Ornithine decarboxylase prevents tumor necrosis factor alpha-induced apoptosis by decreasing intracellular reactive oxygen species. Apoptosis 10 569-581.

[57] Bartel DP. 2004 MicroRNAs: genomics, biogenesis, mechanism, and function. Cell 116 281-297. 
[58] Bulut-Karslioglu A, Biechele S, Jin H, Macrae TA, Hejna M, Gertsenstein M, Song JS and RamalhoSantos M. 2016 Inhibition of mTOR induces a paused pluripotent state. Nature 540 119-123.

[59] Scognamiglio R, Cabezas-Wallscheid N, Thier MC, Altamura S, Reyes A, Prendergast AM, Baumgartner D, Carnevalli LS, Atzberger A, Haas S, van Paleske L, Boroviak T, Worsdorfer P, Essers MAG, Kloz U, Eisenman RN, Edenhofer F, Bertone P, Huber W, van der Hoeven F, Smith A and Trumpp A. 2016 Myc depletion induces a pluripotent dormant state mimicking diapause. Cell 164 668-680.

[60] Hussein AM, Wang Y, Margaretha JML, Song C, Jones DC, Cavanaugh C, Miklas JW, Mahen E, Showalter MR, Ruzzo WL, Fiehn O, Ware CB, Blau CA and Ruohola-Baker H. 2020 Metabolic control over mTOR-dependent diapause-like state. Developmental Cell 52 236-250.

[61] Fenelon JC and Murphy BD. 2018 New functions for old factors: the role of polyamines during the establishment of pregnancy. Reproduction Fertility and Development.

\section{Audience Discussion}

Susanne Ulbrich: Regarding the initiation of the diapause, are they related to the daylight length or lactation? Do you have any idea whether the general control of melatonin by prolactin being influenced by lactation as the main driver, directly on the uterus or indirectly? What kind of evidence do you have regarding the quiescence of the uterus being imposed by either LH or prolactin or whether you have any indication of estrogen signalling?

Jane Fenelon: One of the things I'm interested in is trying to look more at the control of diapause in the tammar. We don't really understand how they switch from this lactational to seasonal quiescence. We know it is involved with melatonin. There's a crossover period, where fewer and fewer animals will reactivate if you remove the pouch young from the teat. There is only a very small short-lived change in oestrogen after reactivation. In mink, you can't reactivate an embryo with progesterone or estrogen: part of the reason was that because there are no receptors in the uterus.

Bruce Murphy: In preliminary experiments, we made cell lines in the mink and we treated them with prolactin.

Jane Fenelon: If you treat them with prolactin, you do get regulation of the corpus luteum (CL).

Pierre Comizzoli: Marilyn, in your presentation, you said at the beginning that what you call a blastocyst is without a definite inner cell mass (ICM).

Marilyn Renfree: There is no ICM in any marsupial blastocyst.

Pierre Comizzoli: after reactivation you can definitely see in your embryo an embryonic disc, ok, so is it really a blastocyst or is it a morula?

Marilyn Renfree: It's not a morula, in those early cleavage stages, the cells are all together, but they don 't have tight junctions, they have not formed a morula. The blastocyst is a hollow ball of about 80-100 cells, each one looks identical. 